\section{(A) Check for updates}

Cite this: Food Funct., 2021, 12, 302

\title{
In vitro neuroprotective potential of terpenes from industrial orange juice by-products
}

\author{
José David Sánchez-Martínez, (ID † † Mónica Bueno, †े $^{\mathrm{a}}$ Gerardo Alvarez-Rivera, ${ }^{\mathrm{a}}$ \\ José Tudela, (D) Elena Ibañez ${ }^{\mathrm{a}}$ and Alejandro Cifuentes ${ }^{\star a}$
}

Citrus sinensis (orange) by-products represent one of the most abundant citric residues from orange juice industrial production, and are a promising source of health-promoting compounds like terpenes. In this work, different extraction solvents have been employed to increase terpene extraction yield and selectivity from this orange juice by-product. A set of bioactivity assays including enzymatic (acetylcholinesterase (AChE), butylcholinesterase (BChE) and lipoxygenase (LOX)) as well as antioxidant (ABTS, reactive oxygen species (ROS) and reactive nitrogen species (RNS)) activity tests have been applied to investigate the neuroprotective potential of these compounds. New fluorescence-based methodologies were developed for $\mathrm{AChE}$ and BChE assays to overcome the drawbacks of these tests when used in vitro to determine the anticholinergic activity of colored extracts. Comprehensive phytochemical profiling based on gas chromatography coupled to quadrupole time of flight mass spectrometry (GC-qTOF-MS) analysis showed ahigh content of mono- and sesquiterpenes in the extracts obtained with ethyl acetate, whereas $n$-heptane extracts exhibited a large amount of triterpenes and carotenoids. From a neuroprotective activity point of view, ethyl acetate extract is the most promising due to its anticholinergic activity and antioxidant capacity. Finally, a multivariate data analysis revealed a good correlation between some monoterpenes (e.g. nerol or limonene) and the antioxidant capacity of the natural extract, while a group of sesquiterpenes (e.g. $\delta$-Cadinene or nootkatone) showed correlation with the observed AChE, BChE and LOX inhibition capacity. Hydrocarbons mono- and sesquiterpenoids reveal high capacity in vitro to cross the blood-brain barrier (BBB).

Received 27th October 2020 Accepted 23rd November 2020 DOI: $10.1039 /$ dOfo02809f

rsc.li/food-function

\section{Introduction}

The valorization of bio-wastes from agricultural activity and industrial processing has become a challenge. For instance, during orange juice production a large amount of solid and semisolid residues such as pulp, peel and seeds are generated. These residues have been shown to be an important source of bioactive compounds. ${ }^{1}$ Among these bioactive compounds, terpenes are a diverse family of organic compounds with a carbon skeleton based on isoprene units. More than 50000 of these molecules have been discovered and classified by the number of carbon atoms in hemiterpenes (C5) monoterpenes (C10), sesquiterpenes (C15), diterpenes (C20), sesterterpenes (C25), triterpenes (C30) and tetraterpenes or carotenoids (C40).

\footnotetext{
${ }^{a}$ Laboratory of Foodomics, Institute of Food Science Research, CIAL, CSIC, Nicolás Cabrera 9, 28049 Madrid, Spain. E-mail: a.cifuentes@csic.es; Fax: +34 910017905; Tel: +34910017955

${ }^{b}$ Department of Biochemistry and Molecular Biology-A, University of Murcia, Espinardo, Murcia, Spain

$\dagger$ These authors contributed equally to this manuscript.
}

Terpenoid fragments could also be present in other natural molecules such as alkaloids, phytosterols, vitamins or phenols. $^{2}$ A great amount of terpenes or terpene derivatives from natural sources have been described to have antioxidant, anti-inflammatory and anti-cholinesterase bioactivity. ${ }^{3}$

Alzheimer's disease (AD) is the main neurodegenerative disorder affecting the elderly accounting for approximately two thirds of all cases of dementia and affecting up to $20 \%$ of individuals older than 80 years. ${ }^{4}$ In fact, $\mathrm{AD}$ is a multifactorial neurological pathology characterized by cognitive impairment, oxidative stress, neuroinflammation, aggregation of amyloidbeta $(\mathrm{A} \beta)$ plaques, hyper-phosphorylation of tau proteins and their aggregation into neurofibrillary tangles. ${ }^{5}$ Cognitive impairment is related to the progressive decline of the acetylcholine (ACh) neurotransmitter in the synaptic cleft. ${ }^{6}$ In addition, recent studies showed the increase of butyrylcholinesterase (BChE) activity in elderly and $\mathrm{AD}$ patients. ${ }^{6}$ Currently, there is no effective treatment for this disease and the palliative treatment consists of increasing acetylcholine levels through a dual inhibitor of acetylcholinesterase (AChE) and BChE enzymes. ${ }^{6,7}$ Furthermore, AChE and BChE are 
linked to the formation of $\mathrm{A} \beta$ plaques, a hallmark of $\mathrm{AD} .^{5} \mathrm{AD}$ patients also show overactivity of lipoxidase (LOX). ${ }^{8}$ This LOX enzyme is linked to neuroinflammation and synaptic dysfunction by production of inflammatory and inmune response mediators. ${ }^{5}$ Inhibition of LOX can lead to less inflammatory and immune response in the brain tissue of $\mathrm{AD}$ patients. ${ }^{9}$ In fact, $\mathrm{AD}$ patients also showed a decrease of superoxide dismutase and glutathione peroxidase, two enzymes with large antioxidant capacity ${ }^{10}$ which leads to exacerbation of oxidative stress and the accumulation of reactive oxygen species (ROS) and reactive nitrogen species (RNS). As a result, neuronal cell death could be caused in the last step by mitochondrial alteration and changes in the permeability of the cellular membrane. ${ }^{10}$ Antioxidants from natural sources are safe and have the capacity to scavenge free radicals like ROS and RNS. ${ }^{11}$ Other than showing the in vitro neuroprotective activity of certain compounds towards different targets in $\mathrm{AD}$, one of the most critical aspects is the ability of these compounds in crossing the blood-brain barrier (BBB), which is related to their pharmacological effectiveness against $\mathrm{AD}$; in this sense, it is important to highlight that around $98 \%$ of pharmacologically active compounds do not cross the BBB. ${ }^{12}$ Different in vitro and in vivo methodologies have been developed to simulate the movement of compounds across the BBB; among them, parallel artificial membrane permeability assay for the blood-brain barrier (PAMPA-BBB) represents a high-throughput non-cell-based permeation test, capable of modeling the rate of transcellular passive diffusion of the BBB. $^{13}$

Therefore, the aim of this work is to investigate the principal by-product from the orange juice industry as a natural source of different families of terpenes. Several extraction solvents are used together with gas chromatography coupled to high-resolution mass spectrometry (GC-q-TOF-MS) for terpene extraction and characterization. The neuroprotective potential of these compounds is investigated through multiple in vitro assays including enzymatic (AChE, BChE and LOX) and antioxidant (ABTS, ROS, RNS) activity tests, together with a PAMPA-BBB assay for the extract showing the highest in vitro neuroprotective potential. Finally, a correlation between the types of terpenes and their antioxidant and neuroprotective activity is suggested for the first time.

\section{Materials and methods}

\subsection{Plant material}

Orange (Citrus sinensis variety Navel Late) residues (peel, pulp and seeds) were kindly provided by J. García Carrión, S.L (Huelva, Spain). Seeds were separated manually, and then pulp and peel were lyophilized in a freeze-drier (Lyobeta 15 Telstar, Terrassa, Spain). Pulp and peel were ground using a laboratory-grade knife mill (Grindomix GM200-Retsch GmbH, Haan, Germany) and sieved to a particle size between 500 and $1000 \mu \mathrm{m}$ (BA 200 N CISA, La Rioja, Spain). Finally, orange byproduct raw materials (peel and pulp powder) were vacuum- packed (C400 Multivac Wolfertschwenden, Germany) and stored at $-18^{\circ} \mathrm{C}$ until their use.

\subsection{Reagents and materials}

HPLC-grade solvents acetonitrile, $n$-heptane ( $\mathrm{NH}$ ), ethyl acetate (ETAC), acetone (Ace) and ethanol (EtOH) were purchased from VWR Chemicals (Barcelona, Spain). Standards of limonene, L- $\alpha$-terpineol, nerol, farnesene, valencene, nootkatone, tocopherols (mixture of $\mathrm{D}-\alpha, \mathrm{D}-\beta, \mathrm{D}-\Delta$, and $\mathrm{D}-\gamma$-tocopherols), campesterol, stigmasterol, and $\gamma$-sitosterol, acetylcholinesterase (AChE) type VI-S from Electrophorus electricus, butyrylcholinesterase from equine serum (BChE), acetylthiocholine iodide (ATCI), linoleic acid (LA), 2,2'-azino-bis (3-ethylbenzothiazoline-6-sulphonic acid) (ABTS), sodium carbonate $\left(\mathrm{Na}_{2} \mathrm{CO}_{3}\right)$, potassium persulfate, Trizma hydrochloride (Tris- $\mathrm{HCl}$ ), disodium phosphate $\left(\mathrm{Na}_{2} \mathrm{HPO}_{4}\right)$, monopotassium phosphate $\left(\mathrm{KH}_{2} \mathrm{PO}_{4}\right)$, sodium nitroprusside dehydrate (SNP), fluorescein sodium salt, sulphanilamide, naphthylethylene diamine dihydrochloride, phosphoric acid, gallic acid, ascorbic acid, quercetin, cholesterol, $n$-dodecane, porcine polar brain lipid (PBL), a PAMPA-BBB 96 well donor plate (Catalog no MAIPNTR10) and a 96 well acceptor plate (Catalog no MATRNPS50) were obtained from Sigma-Aldrich (Madrid, Spain). Folin-Ciocalteu phenol reagent was acquired from Merck (Darmstadt, Germany). Lipoxidase from glycine max (soybean), 4-(amino359 sulfonyl)-7-fluoro-2,1,3-benzoxadiazole (ABD-F), galantamine hydrobromide, and 2,2-azobis(2-amidinopropane) dihydrochloride (AAPH) were purchased from TCI Chemicals (Tokyo, Japan). Ultrapure water was obtained from a Millipore system (Billerica, MA, USA). All the 96-well microplate assays were performed in a spectrophotometer and fluorescent reader (Synergy HT, BioTek Instruments, Winooski, VT, USA).

\subsection{Terpene extraction}

Extracts were obtained through the conventional maceration method. Briefly, $5 \mathrm{~g}$ of orange by-product was mixed with $45 \mathrm{ml}$ of solvents presenting increasing polarity: NH, ETAC, Ace and EtOH. Then, the mixture was placed in an orbital shaker (Compact digital mini rotator, Thermo Scientific, Massachusetts, USA) at $200 \mathrm{rpm}$ for 24 hours (at room temperature preserved from light). Extracts were filtered by using a $0.45 \mu \mathrm{m}$ Nylon filter (Agilent Technologies, California, USA) and evaporated by a gentle nitrogen stream (TurboVap ${ }^{\circledR}$ LV Biotage, Uppsala, Sweden). Finally, the extracts were weighed and stored at $-20{ }^{\circ} \mathrm{C}$ until their analyses. Extractions were performed in triplicate for each solvent.

\subsection{Chemical characterization of terpenes and terpenoids}

2.4.1. Gas chromatography-mass spectrometry (GC-MS) analysis. The samples were dissolved in ethanol at a concentration of $2.5 \mathrm{mg} \mathrm{mL}^{-1}$ and analyzed employing an Agilent 7890B GC system coupled to an Agilent 7200 quadrupole timeof-flight (q-TOF) MS, equipped with an electronic impact (EI) ionization source. The separation was carried out using an Agilent Zorbax DB5-MS + 10 m Duraguard capillary column $(30 \mathrm{~m} \times 250 \mu \mathrm{m} \times 0.25 \mu \mathrm{m})$. The carrier gas was helium at a 
constant flow rate of $0.8 \mathrm{~mL} \mathrm{~min}^{-1}$. The injection volume was $1 \mu \mathrm{L}$ and the injector was operated in splitless mode for $2 \mathrm{~min}$, keeping the injector temperature at $250{ }^{\circ} \mathrm{C}$. The $\mathrm{GC}$ oven was programmed at $60{ }^{\circ} \mathrm{C}$ for $1 \mathrm{~min}$, then its temperature was increased at a rate of $10{ }^{\circ} \mathrm{C} \mathrm{min}^{-1}$ to $325{ }^{\circ} \mathrm{C}$, and the oven was held at this temperature for $10 \mathrm{~min}$. The MS detector was operated in full-scan acquisition mode in an $\mathrm{m} / \mathrm{z}$ scan range of 50-600 Da (5 spectra per second). The temperatures of the transfer line, the quadrupole, and the ion source were set at 290,150 , and $250^{\circ} \mathrm{C}$, respectively. Each extract was injected in duplicate. Systematic mass spectra deconvolution of chromatographic signals was performed using the Agilent Mass Hunter Unknown Analysis tool linked to NIST MS Search v.2.0 and Fiehn Lib databases for the tentative identification of unknown terpenoids. Agilent Mass Hunter Quantitative Analysis software was used to obtain relative abundances for the tentatively identified terpenoids. The selected quantitative and qualitative $\mathrm{m} / \mathrm{z}$ values for each analyte are shown in Table 1. Standards of limonene, L- $\alpha$-terpineol, nerol, farnesene, valencene, nootkatone, tocopherols (mixture of $\mathrm{D}-\alpha, \mathrm{D}-\beta, \mathrm{D}-\Delta$, and $\mathrm{D}-\gamma$-tocopherols), campesterol, stigmasterol, and $\gamma$-sitosterol were diluted in EtOH to adequate concentrations (1-100 $\left.\mathrm{g} \mathrm{mL}^{-1}\right)$ in order to obtain calibration curves. Each calibration curve was recorded at twelve concentrations in triplicate.

2.4.2. Total carotenoid determination. Total carotenoid content was determined by spectrophotometry using a 96-well plate reader, following the method previously reported. ${ }^{14}$ The samples were dissolved in ethanol at a concentration of $5 \mathrm{mg}$ $\mathrm{mL}^{-1}$, and then, $300 \mu \mathrm{L}$ were placed in each well and the absorbance was recorded at a wavelength of $470 \mathrm{~nm}$ based on the characteristic absorbance of carotenoids. An external standard calibration curve of lutein $\left(0.2-20 \mu \mathrm{g} \mathrm{mL}^{-1}\right.$ in ethanol) was used to calculate the total carotenoid content, since lutein is one of the main carotenoids found in orange. ${ }^{15}$ Total carotenoids were expressed as milligram carotenoids per gram extract. Each extract was analyzed in triplicate.

\subsection{Determination of the total phenolic content (TPC)}

The TPC was determined following the Folin-Ciocalteu method $^{16}$ with some modifications. ${ }^{17}$ In brief, an aliquot of $10 \mu \mathrm{L}$ of extract solution ( $5 \mathrm{mg} \mathrm{mL}^{-1}$ in $\mathrm{EtOH}$ ) was mixed and agitated with $600 \mu \mathrm{L}$ of $\mathrm{H}_{2} \mathrm{O}$ and $50 \mu \mathrm{L}$ of Folin-Ciocalteu reagent (undiluted commercial Folin-Ciocalteu reagent). After $1 \mathrm{~min}, 150 \mu \mathrm{L}$ of $\mathrm{Na}_{2} \mathrm{CO}_{3}(20 \% \mathrm{w} / \mathrm{v})$ was added and the volume was made up to $1 \mathrm{~mL}$ with $190 \mu \mathrm{L}$ of $\mathrm{H}_{2} \mathrm{O}$. After $120 \mathrm{~min}$ of incubation at room temperature in darkness, $300 \mu \mathrm{L}$ of each mixture were placed in a 96-well microplate spectrophotometer reader and the absorbance at $760 \mathrm{~nm}$ was measured. A calibration curve was recorded with gallic acid (0-1000 $\mu \mathrm{g}$ gallic acid per $\mathrm{mL}$ EtOH), and TPC results (mean of three replicates) were expressed as gallic acid equivalents $\left(\mathrm{mg}\right.$ GAE $\mathrm{g}^{-1}$ of extract). Each extract was analyzed in triplicate.

\subsection{Anti-cholinergic activity}

The AChE and BChE inhibitory capacity of the extracts was measured by fluorescent enzyme kinetics based on Ellman's method with some modifications. ${ }^{18}$ In this work, ABD-F replaces 5,5'-dithio-bis(2-nitrobenzoic acid) (DNTB) reagent. Each well was filled with $100 \mu \mathrm{L}$ of extract sample at different concentrations $\left(150 \mu \mathrm{g}-1500 \mu \mathrm{g} \mathrm{mL}{ }^{-1}\right)$ in EtOH $/ \mathrm{H}_{2} \mathrm{O}(1: 1, \mathrm{v} / \mathrm{v})$, $100 \mu \mathrm{L}$ of buffer $(150 \mathrm{mM}$ Tris- $\mathrm{HCl} \mathrm{pH}=8)$ and $25 \mu \mathrm{L}$ of $0.8 \mathrm{U}$ $\mathrm{mL}^{-1}$ AChE or BChE in buffer. The mixture was incubated for 10 minutes. Reaction started by adding $25 \mu \mathrm{L}$ of ABD-F $(125 \mu \mathrm{M})$ in buffer and $50 \mu \mathrm{L}$ of ATCI at a concentration of the $K_{\mathrm{M}}$ (Michaelis-Menten constant) value in $\mathrm{H}_{2} \mathrm{O}$. The $K_{\mathrm{M}}$ constant is numerically equal to the substrate concentration at which the reaction rate is half of the maximum velocity rate. The fluorescence readings were recorded at $\lambda_{\text {excitation }}=389 \mathrm{~nm}$ and $\lambda_{\text {emission }}=513 \mathrm{~nm}$ every minute for 10 minutes at $37^{\circ} \mathrm{C}$. This kinetic measurement is needed to obtain the $V_{\text {mean }}$ value. $V_{\text {mean }}$ corresponds to enzymatic mean velocity achieved during kinetic measurement. The percentage of inhibition degree (ID\%) was calculated through eqn (1):

$$
\mathrm{ID} \%=\frac{V_{0}-V_{1}}{V_{0}} \times 100
$$

where $V_{0}$ and $V_{1}$ are the $V_{\text {mean }}$ of enzyme kinetics without and with the extract sample, respectively. Galantamine hydrobromide in $\mathrm{EtOH} / \mathrm{H}_{2} \mathrm{O}(1: 1, \mathrm{v} / \mathrm{v})$ was used as the reference inhibitor for both enzymes.

The $K_{\mathrm{M}}$ value was measured by mixing $100 \mu \mathrm{L}$ of ATCI at different concentrations $(0.4-4 \mathrm{mM})$ in $\mathrm{H}_{2} \mathrm{O}, 50 \mu \mathrm{L}$ of pure EtOH and $100 \mu \mathrm{L}$ of buffer. Reaction was started by adding $25 \mu \mathrm{L}$ of ABD-F $(125 \mu \mathrm{M})$ in buffer and $25 \mu \mathrm{L}$ of 0.8 $\mathrm{U} \mathrm{mL}^{-1}$ AChE or BChE in buffer, in each well. $V_{\text {mean }}$ and $K_{\mathrm{M}}$ values were calculated using Gen5 ${ }^{\mathrm{TM}}$ version 2.0 Data Analysis software from BioTek Instruments, Winooski, VT, USA.

\subsection{Lipoxidase (LOX) inhibitory capacity}

LOX inhibition activity was measured through a fluorescence assay based on enzyme kinetics, inspired by the methodology reported by Whent et al. in $2010 .^{19}$ The assay solution consists of $100 \mu \mathrm{L}$ of the extract sample at different concentrations $\left(100 \mu \mathrm{g}-1000 \mu \mathrm{g} \mathrm{mL} \mathrm{m}^{-1}\right)$ in $\mathrm{EtOH} / \mathrm{H}_{2} \mathrm{O}(1: 1, \mathrm{v} / \mathrm{v}), 75 \mu \mathrm{L}$ of fluorescein $(1 \mu \mathrm{M})$ in buffer (150 mM Tris-HCl pH 9), $60 \mu \mathrm{L}$ of LOX

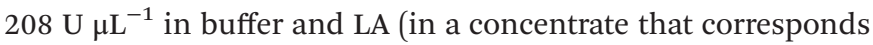
to the $K_{\mathrm{M}}$ value) in $\mathrm{EtOH} / \mathrm{H}_{2} \mathrm{O}(1: 1, \mathrm{v} / \mathrm{v})$, in each well. The fluorescence measurements were registered at $\lambda_{\text {excitation }}=485 \mathrm{~nm}$ and $\lambda_{\text {emission }}=530 \mathrm{~nm}$ every minute for 15 minutes at $25{ }^{\circ} \mathrm{C}$. Quercetin was used as the reference inhibitor. ID\% was calculated also using eqn (1). The $K_{\mathrm{M}}$ value was measured by mixing $100 \mu \mathrm{L}$ of LA $(6.5 \mathrm{mM})$ in $\mathrm{EtOH} / \mathrm{H}_{2} \mathrm{O}(1: 1, \mathrm{v} / \mathrm{v}), 100 \mu \mathrm{L}$ of EtOH/ $\mathrm{H}_{2} \mathrm{O}(1: 1, \mathrm{v} / \mathrm{v}), 75 \mu \mathrm{L}$ of fluorescein $(1 \mu \mathrm{M})$ in buffer and $60 \mu \mathrm{L}$ of LOX $208 \mathrm{U}^{-1} \mathrm{~L}^{-1}$ in buffer, in each well.

\subsection{Antioxidant activity assays (ABTS, ROS and RNS scavenging capacity)}

2.8.1. ABTS assay. The $\mathrm{ABTS}^{{ }^{++}}$radical is generated by reacting ABTS with potassium persulfate in the dark at room temperature for 16 hours. $^{20}$ In the microplate version, $100 \mu \mathrm{L}$ of extracts dissolved at different concentrations $(50 \mu \mathrm{g}-500 \mu \mathrm{g})$ 


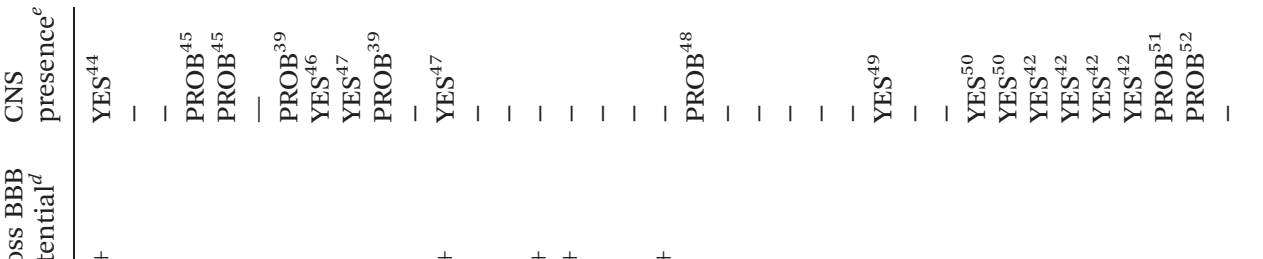

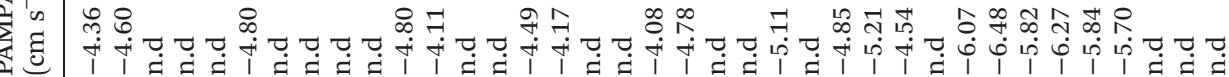

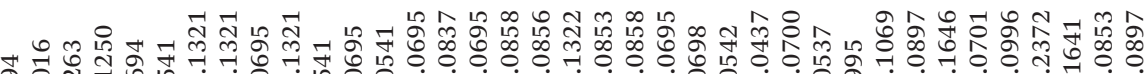

过 人)

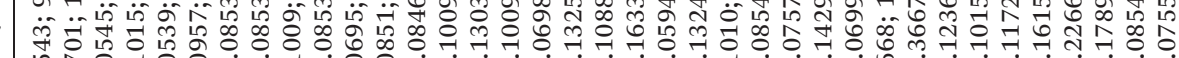

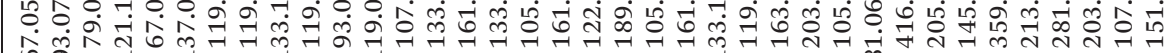

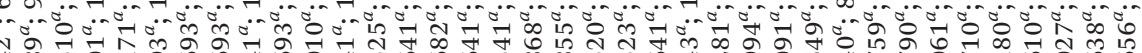
7 क

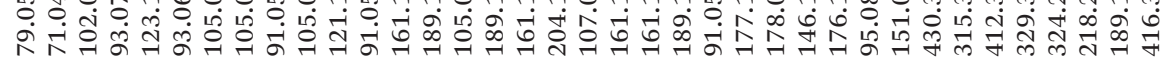

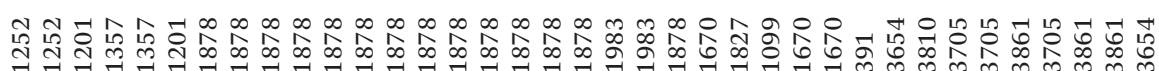

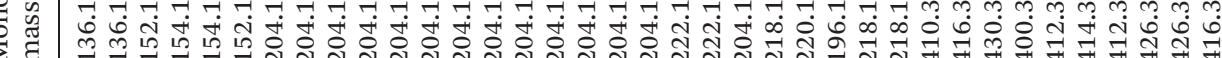

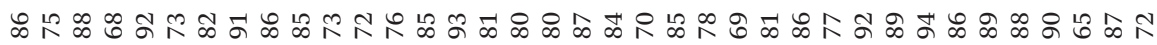

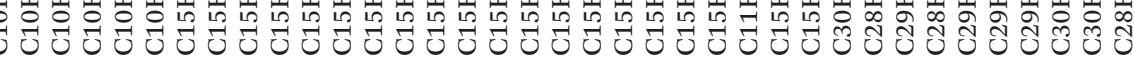

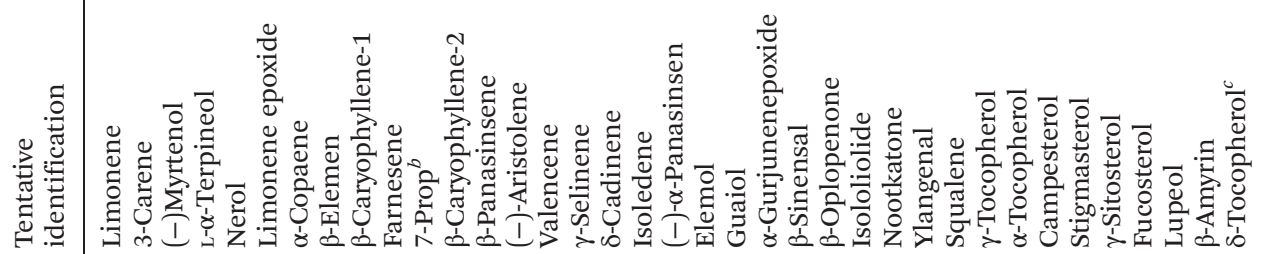

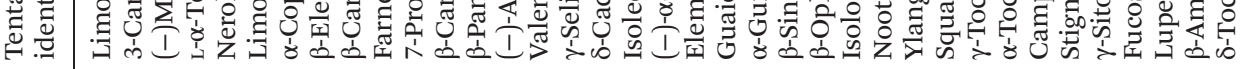

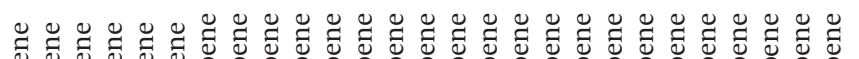

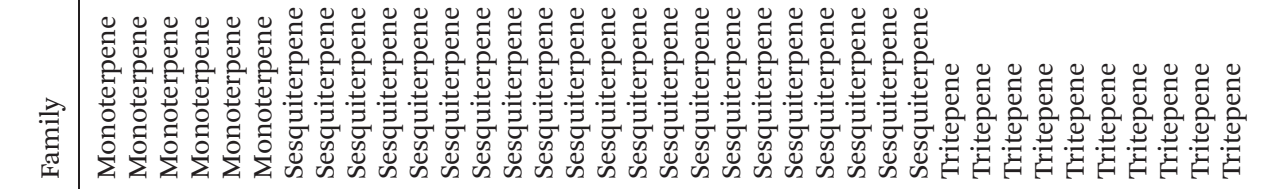

$\dot{2}$

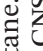

:용

范

$\vec{D}_{\square}$

疍.:

索

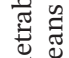

ठี

ن

ปัँ

学莒

㟧

这?

웜

웡

政

西,

ํํำ

$\rightarrow$ i

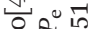

C.

인 11

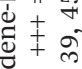

:

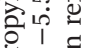

定 $\wedge$

ธ요

声舟

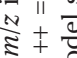
的荐 莺

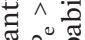

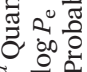


in pure $\mathrm{EtOH}$ and $250 \mu \mathrm{L}$ of $\mathrm{ABTS}^{*+}(7 \mathrm{mM})$ in $5 \mathrm{mM}$ phosphate buffer $(\mathrm{pH}=7.5)$ were mixed in each well. After $45 \mathrm{~min}$ of incubation in the dark at room temperature, the absorbance at $734 \mathrm{~nm}$ was measured. Ascorbic acid was used as the reference standard (control samples). The percentage of inhibition of the $\mathrm{ABTS}^{\circ}$ radical from the extract sample was measured according to the following eqn (2):

$$
\begin{aligned}
\text { Inhibition } \%= & \frac{\left(A_{\text {Sample }}-A_{\text {Blank }}\right)-\left(A_{\text {Control }}-A_{\text {Control Blank }}\right)}{\left(A_{\text {Control }}-A_{\text {Control Blank }}\right)} \\
& \times 100
\end{aligned}
$$

where $A_{\text {Sample }}$ and $A_{\text {Blank }}$ are the absorbance of the extract sample with and without $\mathrm{ABTS}^{\circ+}$, respectively. $A_{\text {Control }}$ and $A_{\text {Control blank }}$ are the absorbance of ascorbic acid with and without $\mathrm{ABTS}^{\bullet+}$, respectively.

2.8.2. ROS scavenging capacity. The oxygen radical absorbance capacity (ORAC) method was carried out according to Ou et al. $2001 .^{21}$ Reaction mixtures in the wells contained the following reagents: $100 \mu \mathrm{L}$ of extract sample at different concentrations $\left(5 \mu \mathrm{g}-50 \mu \mathrm{g} \mathrm{mL}{ }^{-1}\right)$ in $\mathrm{EtOH} / \mathrm{H}_{2} \mathrm{O}(1: 9, \mathrm{v} / \mathrm{v}), 100 \mu \mathrm{L}$ of AAPH (590 mM) in $30 \mathrm{mM}$ phosphate-buffered saline (PBS) at $\mathrm{pH}=7.5,25 \mu \mathrm{L}$ of fluorescein $(10 \mu \mathrm{M})$ in PBS buffer and $100 \mu \mathrm{L}$ of PBS buffer. Fluorescence was measured $\left(\lambda_{\text {excitation }}=\right.$ $485 \mathrm{~nm} ; \lambda_{\text {emission }}=530 \mathrm{~nm}$ ) every 5 minutes at $37^{\circ} \mathrm{C}$ for 1 hour. Ascorbic acid was used as the reference standard. The capacity of each extract for scavenging peroxyl radicals was calculated through the inhibition percentage of the difference between the area under the curve (AUC) of fluorescence decay in the presence $\left(\mathrm{AUC}_{\text {sample }}\right)$ or absence $\left(\mathrm{AUC}_{\text {control }}\right)$ of the sample (eqn (3)).

$$
\text { Inhibition } \%=\frac{\mathrm{AUC}_{\text {Control }}-\mathrm{AUC}_{\text {Sample }}}{\mathrm{AUC}_{\text {Control }}} \times 100
$$

The AUC was calculated using the following eqn (4):

$$
\mathrm{AUC}=0.5+\sum f_{i} / f_{0}
$$

where $f_{0}$ is the initial fluorescence at 0 minutes and $f_{i}$ is fluorescence every 5 minutes.

2.8.3. RNS scavenging capacity. RNS scavenging capacity was measured following the nitric oxide (NO) radical scavenging assay. ${ }^{22}$ Mixtures of $100 \mu \mathrm{L}$ of the extract sample at different concentrations $\left(150 \mu \mathrm{g}-1500 \mu \mathrm{g} \mathrm{mL} \mathrm{m}^{-1}\right)$ in $\mathrm{EtOH} / \mathrm{H}_{2} \mathrm{O}$ $(1: 3, \mathrm{v} / \mathrm{v})$ and $50 \mu \mathrm{L}$ of SNP $(5 \mathrm{mM})$ in $30 \mathrm{mM}$ PBS $(\mathrm{pH}=7.5)$ were mixed in each well. The mixture was incubated for 120 minutes under light at room temperature. Then, $100 \mu \mathrm{L}$ of Griess reagent (500 mg sulphanilamide, $50 \mathrm{mg}$ naphthylethylene diamine dihydrochloride and $1.25 \mathrm{~mL}$ of phosphoric acid in $48.5 \mathrm{~mL}$ of $\mathrm{H}_{2} \mathrm{O}$ ) was added to each well and absorbance at $734 \mathrm{~nm}$ was recorded in order to measure the nitrite ion concentration. Ascorbic acid was used as the reference standard. The NO scavenging capacity of each extract was expressed through inhibition \% calculated by eqn (2).

\subsection{Parallel artificial membrane permeability assay for the blood-brain barrier (PAMPA-BBB)}

The PAMPA-BBB experiment was performed according to the study by Könczöl et al., 2016. ${ }^{23}$ In brief, $300 \mu \mathrm{L}$ of $10 \mathrm{mg}$ $\mathrm{mL}^{-1}$ extract was mixed with $400 \mu \mathrm{L}$ of buffer (PBS pH 7.4, $10 \mathrm{mM}$ ), in order to obtain the stock of the initial donor solution. Then, the filter membrane of the donor plate was coated with $5 \mu \mathrm{L}$ of BBB solution ( $8 \mathrm{mg}$ of PBL and $4 \mathrm{mg}$ of cholesterol were dissolved in $600 \mu \mathrm{L} n$-dodecane). Afterwards, the acceptor plate was filled with $350 \mu \mathrm{L}$ of buffer, and the donor plate was carefully placed on the acceptor plate to form a "sandwich". After that, $200 \mu \mathrm{L}$ of stock donor solution was placed in the donor plate and the "sandwich" was covered and incubated for $5 \mathrm{~h}$ at $37{ }^{\circ} \mathrm{C}$, out of direct light (see Fig. 1). After incubation, plates were separated and $150 \mu \mathrm{L}$ were taken for both plates, placed into a vial, and dried to obtain acceptor and donor solutions. Dried acceptor and donor solutions were reconstituted in $50 \mu \mathrm{L}$ of EtOH that were used for GC/MS analysis. Permeability across the artificial BBB of the studied compounds was calculated through the equation given by $\mathrm{X}$. Chen et al., 2008, ${ }^{24}$ with slight modifications in concentration parameters.

$$
P_{\mathrm{e}}=\frac{-\ln \left[1-C_{\mathrm{A}}(t) / C_{\text {equilibrium }}\right]}{A \times\left(\frac{1}{V_{\mathrm{D}}}+\frac{1}{V_{\mathrm{A}}}\right) \times t}
$$

where $P_{\mathrm{e}}$ is permeability in $\mathrm{cm} \mathrm{s}^{-1} . A=$ effective filter area $=$ $f \times 0.3 \mathrm{~cm}^{2} ; V_{\mathrm{D}}=$ donor well volume $=0.2 \mathrm{ml} ; V_{\mathrm{A}}=$ acceptor well volume $=0.35 \mathrm{ml} ; t=$ incubation time $(\mathrm{s})=14400 ; C_{\mathrm{A}(t)}=$ compound concentration in the acceptor well at time $t ; C_{\mathrm{D}(t)}=\mathrm{com}$ pound concentration in the donor well at time $t$. $C_{\text {equilibrium }}$ is calculated as follows:

$$
C_{\text {equilibrium }}=\left[C_{\mathrm{D}(t)} \times V_{\mathrm{D}}+C_{\mathrm{A}(t)} \times V_{\mathrm{A}}\right] /\left(V_{\mathrm{D}}+V_{\mathrm{A}}\right)
$$

\subsection{Statistical analysis}

Three independent assays of each extraction replicate were performed for enzymatic and antioxidant methodologies. To estimate $\mathrm{IC}_{50}$ values $\left(\mu \mathrm{g} \mathrm{mL}^{-1}\right)$, the percentage of inhibition degree (ID\%) of each sample was measured at seven different concentrations in order to obtain concentration-dependent curves by linear regression. Calibration curves of the standards were considered linear if $R^{2}>0.99$ (Microsoft excel 2010, Washington USA). All experimental results are given as mean \pm standard deviation (mean $\pm \mathrm{SD}$ ). Experimental data results were analyzed by ANOVA and means were compared by Tukey's HSD (SPSS statics V15 IBM, New York, USA). The value of $p<$ 0.05 was considered statistically significant, indicated by different alphabetical letters along means in tables. Principal component analysis (PCA) was carried out using statistical software The Unscrambler V9.7 (CAMO Software AS, Oslo, Norway). 


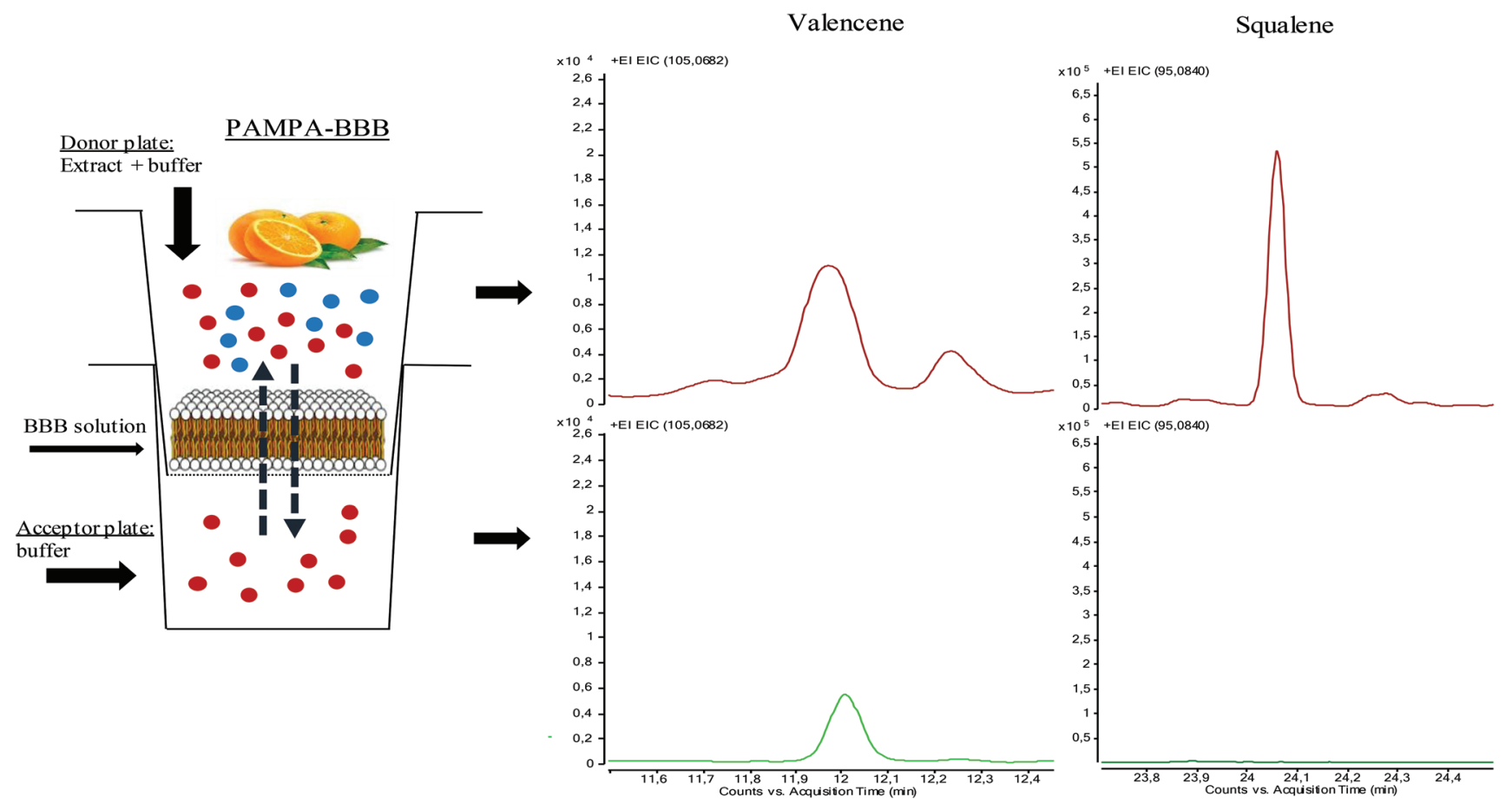

Fig. 1 PAMPA-BBB scheme. Valencene and squalene (total counts) detected in donor and acceptor wells. Results for BBB penetrability of the different compounds are given in Table 1.

\section{Results and discussion}

Four organic solvents (heptane, ethyl acetate, acetone and ethanol), covering a wide range of polarities, were screened to obtain extracts with different terpenic profiles from the orange juice by-product applying a conventional maceration method (section 2.1). The target extracts were subjected to comprehensive chemical characterization and to a set of in vitro biological activity assays as discussed below.

\subsection{Terpene content in the organic extract}

Untargeted screening analysis of GC-q-TOF-MS data was carried out to search for the GC-amenable terpenoid compounds in the orange juice by-product extracts. In order to facilitate discussion, terpenoids were classified into families according to the number of isoprene units involved in the chemical structure. Tentative identification was proposed on the basis of the positive match of the experimental mass spectra with theoretical MS data from databases, calculated mass accuracy for the $[\mathrm{M}]^{+}$molecular ion, and data reported in the literature. GC-HRMS parameters such as retention time, match factor values given by MS databases, monoisotopic mass and main MS/MS fragments are shown in Table 1 for the tentatively identified terpenoids in ethyl acetate extracts. Satisfactory reliability in identification was observed, considering that seventy-two percent of the compounds showed a match factor value higher than $80 \%$. For comparative purposes, terpenoid peak area values were interpolated with their corresponding or similar structural terpenoid standard cali- bration curve to calculate their concentration in $\mathrm{ng} \mathrm{mL}^{-1}$ (Table 2). Concentration was used to determine the capacity of the different solvents to extract the target terpenoids. Table 2 shows quantitative results in terms of $\mathrm{ng} \mathrm{mL}^{-1} \pm$ relative standard deviation. As can be seen by the sum of concentration obtained for the different terpenoids in the tested solvents, in general ETAC and NH show the greatest capacity to extract terpenoids. ETAC extract (chromatogram shown in Fig. 2) showed the highest amount of monoterpenes, mainly $\mathrm{L}-\alpha$-terpineol, and low boiling point sesquiterpenes as valencene. In addition, ETAC extract also presented a high content of triterpenes, namely $\alpha$-tocopherol and $\gamma$-sitosterol. On the other hand, NH extracted a higher amount of high boiling point sesquiterpenes, and triterpenes. The large amount of $\alpha$-tocopherol and $\gamma$-sitosterol obtained in $\mathrm{NH}$ extract is particularly remarkable. Ace extract contains similar amounts of limonene to ETAC and $\mathrm{NH}$ extracts. EtOH extract was mainly composed of limonene and (-)myrtenol in comparison with other extracts. Although EtOH is the worst solvent for terpenoid extraction, it is the one that achieves the highest global extraction yield (Table 3 ). This can be explained by the composition of orange peels which are rich in pectin, cellulose, hemicellulose and soluble sugars ${ }^{25}$ that are commonly extracted from food by-products with polar solvents, mainly water and ethanol or their mixtures. ${ }^{26}$ This fact also explains the polarity impact on the extraction yield shown in Table 3, in agreement with other works carried out with orange peels. ${ }^{27}$

Considering the thermolability of carotenoid compounds under GC analysis, a spectrophotometric method was alterna- 
Table 2 Concentration ( $\mathrm{ng} \mathrm{mL} \mathrm{m}^{-1}$ and \%) of tentatively identified terpenes in the different organic extracts

\begin{tabular}{|c|c|c|c|c|c|c|c|c|c|c|c|}
\hline \multirow[b]{3}{*}{ Peak no } & \multirow[b]{3}{*}{$\begin{array}{l}\text { Ret. time } \\
\text { (min) }\end{array}$} & \multirow[b]{3}{*}{ Tentative identification } & \multicolumn{8}{|c|}{ Concentration $\mathrm{ng} \mathrm{mL}^{-1}$} & \multirow[b]{3}{*}{ Ref. } \\
\hline & & & \multicolumn{2}{|l|}{ EtOH } & \multicolumn{2}{|l|}{ Ace } & \multicolumn{2}{|l|}{ ETAC } & \multicolumn{2}{|l|}{$\mathrm{NH}$} & \\
\hline & & & $\begin{array}{l}\text { Conc. } \\
\text { (RSD, \%) }\end{array}$ & $\begin{array}{l}\text { Conc. } \\
(\%)\end{array}$ & $\begin{array}{l}\text { Conc. } \\
\text { (RSD, \%) }\end{array}$ & $\begin{array}{l}\text { Conc. } \\
(\%)\end{array}$ & Conc. (RSD, \%) & $\begin{array}{l}\text { Conc. } \\
(\%)\end{array}$ & $\begin{array}{l}\text { Conc. } \\
\text { (RSD, \%) }\end{array}$ & $\begin{array}{l}\text { Conc. } \\
(\%)\end{array}$ & \\
\hline \multicolumn{12}{|c|}{ Monoterpenes } \\
\hline 1 & 5.856 & Limonene $^{a}$ & $29.4(10)$ & 14.0 & $26.3(11)$ & 3.3 & $25.0(8)$ & 1.5 & $1.88(5)$ & 0.09 & 1 and 53 \\
\hline 2 & 6.688 & 3-Carene ${ }^{a}$ & $2.56(4)$ & 1.2 & $4.12(8)$ & 0.5 & $5.27(4)$ & 0.3 & $0.98(6)$ & 0.04 & 1 and 53 \\
\hline 3 & 7.164 & $(-)$ Myrtenol $^{b}$ & $7.29(12)$ & 3.4 & $4.11(6)$ & 0.5 & $1.25(1)$ & 0.1 & 0.00 & & - \\
\hline 4 & 8.046 & $\mathrm{~L}-\alpha$-Terpineol ${ }^{b}$ & $7.89(10)$ & 3.7 & $15.3(10)$ & 1.9 & $31.8(6)$ & 1.9 & $11.1(7)$ & 0.51 & 53 \\
\hline 5 & 8.395 & Nerol $^{c^{1}}$ & $5.28(6)$ & 2.5 & $5.63(3)$ & 0.7 & $6.03(5)$ & 0.4 & $5.03(2)$ & 0.23 & 1 and 53 \\
\hline \multirow[t]{2}{*}{6} & 10.075 & Limonene epoxide $^{c}$ & $0.91(6)$ & 0.4 & $1.57(1)$ & 0.2 & $2.88(5)$ & 0.2 & $2.02(5)$ & 0.09 & - \\
\hline & & $\sum$ Monoterpenes & $53.3(5)$ & 25.5 & $57.2(3)$ & 7.0 & $72.2(8)$ & 4.4 & $21.1(4)$ & 0.96 & \\
\hline \multicolumn{12}{|c|}{ Sesquiterpenes } \\
\hline 7 & 10.480 & $\alpha$-Copaene ${ }^{d}$ & $1.02(13)$ & 0.4 & $1.15(3)$ & 0.1 & $2.04(1)$ & 0.1 & $1.16(2)$ & 0.05 & 1 \\
\hline 8 & 10.631 & $\beta$-Elemen ${ }^{d}$ & $1.19(4)$ & 0.5 & $1.70(8)$ & 0.2 & $3.16(1)$ & 0.2 & $2.17(5)$ & 0.10 & 1 and 53 \\
\hline 9 & 11.074 & $\beta$-Caryophyllene- $1^{d}$ & $1.30(2)$ & 0.6 & $1.88(5)$ & 0.2 & $3.96(13)$ & 0.2 & $2.29(6)$ & 0.10 & 1 and 53 \\
\hline 10 & 11.191 & Farnesene $^{d}$ & $1.09(7)$ & 0.5 & $1.47(4)$ & 0.2 & $2.10(8)$ & 0.1 & $1.49(10)$ & 0.07 & 53 \\
\hline 11 & 11.342 & 7-Prop ${ }^{d}$ & $0.41(8)$ & 0.2 & $0.84(2)$ & 0.1 & $1.20(8)$ & 0.1 & $0.99(11)$ & 0.05 & - \\
\hline 12 & 11.419 & $\beta$-Caryophyllene- $2^{d}$ & $1.08(1)$ & 0.5 & $1.79(1)$ & 0.2 & $3.12(6)$ & 0.2 & $1.81(10)$ & 0.08 & 1 and 53 \\
\hline 13 & 11.778 & $\beta$-Panasinsene ${ }^{d}$ & $0.84(9)$ & 0.4 & $0.90(2)$ & 0.1 & $1.15(3)$ & 0.1 & $0.98(3)$ & 0.04 & 1 \\
\hline 14 & 11.875 & $(-)$-Aristolene $e^{d}$ & $1.21(7)$ & 0.5 & $1.99(12)$ & 0.2 & $3.58(5)$ & 0.2 & $2.80(2)$ & 0.13 & - \\
\hline 15 & 11.998 & Valencene $^{d}$ & $6.17(9)$ & 2.9 & $12.2(7)$ & 1.5 & $41.4(8)$ & 2.5 & $27.1(14)$ & 1.24 & 1 and 53 \\
\hline 16 & 12.033 & $\gamma$-Selinene ${ }^{d}$ & $1.25(9)$ & 0.6 & $1.93(6)$ & 0.2 & $4.26(5)$ & 0.3 & $3.81(3)$ & 0.17 & 1 \\
\hline 17 & 12.116 & $\delta$-Cadinene ${ }^{d}$ & $0.80(5)$ & 0.3 & $0.90(4)$ & 0.1 & $1.09(9)$ & 0.1 & $1.02(6)$ & 0.05 & 1 and 53 \\
\hline 18 & 12.267 & Isoledene $^{d}$ & $0.82(5)$ & 0.3 & $0.98(10)$ & 0.1 & $1.25(0)$ & 0.1 & $1.16(13)$ & 0.05 & - \\
\hline 19 & 12.324 & $(-)-\alpha$-Panasinsen ${ }^{d}$ & $1.16(8)$ & 0.5 & $1.87(14)$ & 0.2 & $3.74(4)$ & 0.2 & $3.08(8)$ & 0.14 & 1 \\
\hline 20 & 12.649 & Elemol $^{e}$ & $1.43(13)$ & 0.6 & $2.61(6)$ & 0.3 & $4.30(13)$ & 0.3 & $5.19(8)$ & 0.24 & - \\
\hline 21 & 13.598 & Guaiol $^{e}$ & 0.00 & & $0.83(4)$ & 0.1 & $0.93(5)$ & 0.1 & $0.92(0)$ & 0.04 & - \\
\hline 22 & 14.068 & $\alpha$-Gurjunenepoxide ${ }^{d}$ & $0.92(8)$ & 0.4 & $1.33(1)$ & 0.2 & $1.90(7)$ & 0.1 & $2.20(9)$ & 0.10 & 1 \\
\hline 23 & 14.292 & $\beta$-Sinensal ${ }^{e}$ & $2.28(7)$ & 1.0 & $7.25(5)$ & 0.9 & $13.4(3)$ & 0.8 & $18.1(11)$ & 0.83 & 1 \\
\hline 24 & 14.410 & $\beta$-Oplopenone ${ }^{e}$ & 0.00 & & $1.26(1)$ & 0.2 & $1.57(4)$ & 0.1 & $1.77(6)$ & 0.08 & - \\
\hline 25 & 15.214 & isololiolide $^{e}$ & 0.00 & & $1.02(6)$ & 0.1 & $1.38(7)$ & 0.1 & $1.13(10)$ & 0.05 & - \\
\hline 26 & 15.617 & Nootkatone $e^{e}$ & $1.92(3)$ & 0.9 & $4.75(13)$ & 0.6 & $8.97(2)$ & 0.5 & $11.1(3)$ & 0.51 & 53 and 54 \\
\hline \multirow[t]{2}{*}{27} & 15.751 & Ylangenal $^{e}$ & $1.12(7)$ & 0.5 & $1.62(9)$ & 0.2 & $2.24(1)$ & 0.1 & $2.52(2)$ & 0.12 & - \\
\hline & & $\sum$ Sesquiterpene & $26.0(9)$ & 12.4 & $50.3(14)$ & 6.2 & $106.8(8)$ & 6.5 & $92.9(14)$ & 4.25 & \\
\hline \multicolumn{12}{|c|}{ Triterpenes } \\
\hline 28 & 24.102 & Squalene $e^{g}$ & $4.63(9)$ & 2.2 & $40.2(4)$ & 5.0 & $115.4(1)$ & 7.0 & $176.9(6)$ & 8.08 & - \\
\hline 29 & 25.759 & $\gamma$-Tocopherol ${ }^{f}$ & 3.02 (1) & 1.4 & $9.96(8)$ & 1.2 & $24.4(2)$ & 1.5 & $36.2(5)$ & 1.66 & 55 \\
\hline 30 & 26.272 & $\alpha$-Tocopherol ${ }^{g}$ & $51.2(6)$ & 24.5 & $267.5(13)$ & 33.0 & $610.8(1)$ & 37.2 & $875.4(1)$ & 40.00 & 55 \\
\hline 31 & 26.992 & Campesterol $^{h}$ & $5.93(9)$ & 2.8 & $19.2(3)$ & 2.4 & $42.0(10$ & 2.6 & $57.5(8)$ & 2.63 & 54 \\
\hline 32 & 27.157 & Stigmasterol $^{i}$ & $3.17(5)$ & 1.5 & $10.6(4)$ & 1.3 & $23.0(1)$ & 1.4 & $32.4(0)$ & 1.48 & 54 \\
\hline 33 & 27.548 & $\gamma$-Sitosterol ${ }^{j}$ & $41.5(1)$ & 19.8 & $246.1(3)$ & 30.3 & 380.1 (1) & 23.1 & $539.3(9)$ & 24.64 & 54 \\
\hline 34 & 27.639 & Fucosterol $^{i}$ & $8.57(5)$ & 4.1 & $32.6(2)$ & 4.0 & $85.4(7)$ & 5.2 & $126.7(3)$ & 5.79 & 54 \\
\hline 35 & 27.874 & Lupeol $^{i}$ & $2.70(2)$ & 1.2 & $16.1(1)$ & 2.0 & $36.9(5)$ & 2.2 & $50.6(1)$ & 2.31 & - \\
\hline 36 & 28.186 & $\beta$-Amyrin ${ }^{i}$ & $0.47(1)$ & 0.2 & $3.30(1)$ & 0.4 & $5.78(9)$ & 0.4 & $6.5(13)$ & 0.30 & - \\
\hline \multirow[t]{2}{*}{37} & 35.471 & $\delta$-Tocopherol ${ }^{f}$ & $8.52(7)$ & 4.0 & $58.0(6)$ & 7.2 & $138.7(11)$ & 8.4 & $172.5(0)$ & 7.89 & - \\
\hline & & $\sum$ Triterpene & $129.8(2)$ & 62.0 & $703.8(10)$ & 86.7 & $1462.9(7)$ & 89.1 & $2074.4(6)$ & 94.79 & \\
\hline
\end{tabular}

${ }^{a}$ Quantified by the limonene standard calibration curve parameter. ${ }^{b}$ Quantified by the L- $\alpha$-Terpineol standard calibration curve parameter. ${ }^{c}$ Quantified by the nerol standard calibration curve parameter. ${ }^{d}$ Quantified by the valencene standard calibration curve parameter. ${ }^{e}$ Quantified by the nootkatone standard calibration curve parameter. ${ }^{f}$ Quantified by the $\gamma$-tocopherol standard calibration curve parameter. ${ }^{g}$ Quantified by the $\alpha$-tocopherol standard calibration curve parameter. ${ }^{h}$ Quantified by the campesterol standard calibration curve parameter. ${ }^{i}$ Quantified by the stigmasterol standard calibration curve parameter. ${ }^{j}$ Quantified by the $\gamma$-sitosterol standard calibration curve parameter.

tively proposed to determine the total carotenoid content of the target extracts. As can be seen in Table 3, the more nonpolar the solvent, the higher the total carotenoid value. The extraction efficiency of carotenoids depends on the vegetal matrix and the structure of the carotenoid to be extracted. ${ }^{28}$ Non-polar carotenoids such as carotenoid esters, abundantly present in orange, are more effectively extracted using nonpolar solvents like $\mathrm{NH}^{28}$ The opposite occurs with TPC that are preferentially extracted with more polar solvents such ethanol and acetone (Table 3), as it has been already reported by other authors in orange by-products. ${ }^{27}$

\subsection{In vitro assays}

Although studies have been previously reported in the literature concerning the terpenoid content in diverse orange byproduct matrices, ${ }^{1,29}$ to the best of our knowledge, the investi- 


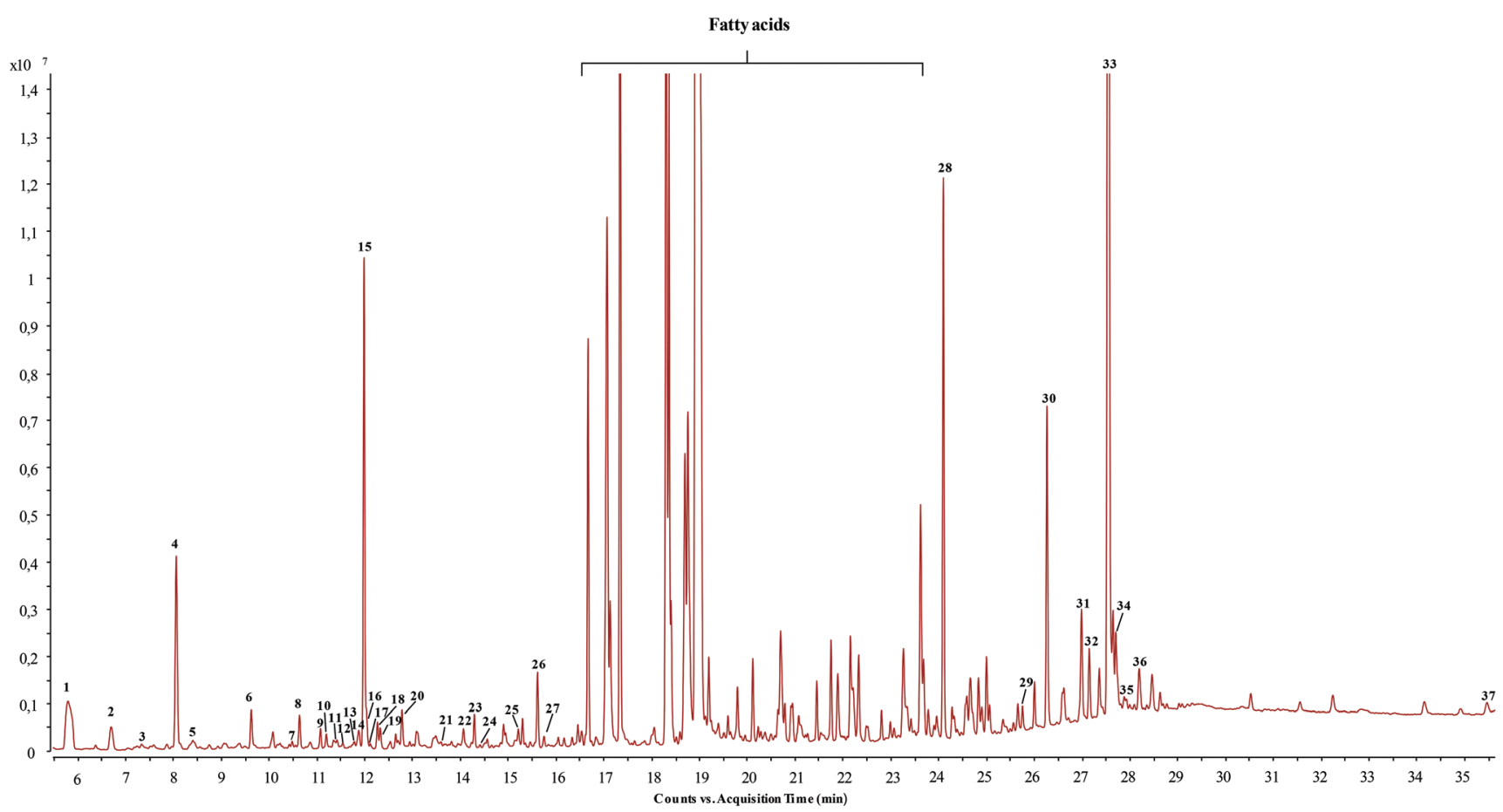

Fig. 2 Main peaks observed by GC-QTOF-MS analysis of the orange by-product dissolved in ethyl acetate $\left(2.5 \mathrm{mg} \mathrm{mL}^{-1}\right)$. For peak assignment, see Table 1.

Table 3 Effect of the solvent type on the yield (\%), total phenolic content and total carotenoid content of orange by-product extracts

\begin{tabular}{llll}
\hline Extract & Yield $(\%)$ & TPC $\left(\mathrm{mg} \mathrm{GA} \mathrm{g}^{-1}\right.$ extract $)$ & $\begin{array}{l}\text { Total carotenoids } \\
\left(\mathrm{mg} \mathrm{g}^{-1} \text { extract }\right)\end{array}$ \\
\hline EtOH & $16.21 \pm 1.09^{\mathrm{a}}$ & $76.78 \pm 3.79^{\mathrm{a}}$ & $1.48 \pm 0.02^{\mathrm{d}}$ \\
Ace & $1.48 \pm 0.16^{\mathrm{b}}$ & $60.42 \pm 4.62^{\mathrm{b}}$ & $7.39 \pm 0.08^{\mathrm{c}}$ \\
ETAC & $0.51 \pm 0.03^{\mathrm{b}}$ & $39.45 \pm 1.31^{\mathrm{c}}$ & $9.87 \pm 0.03^{\mathrm{b}}$ \\
NH & $0.26 \pm 0.00^{\mathrm{b}}$ & $24.25 \pm 0.28^{\mathrm{d}}$ & $26.87 \pm 0.06^{\mathrm{a}}$
\end{tabular}

Different letters in the same column show significant differences $(p<$ 0.05).

gation presented in this work on the extraction selectivity towards diverse families of terpenes linked to their different bioactivity is reported here for the first time.

3.2.1. AChE and BChE in vitro assays. The four orange juice by-product extracts were tested against AChE and BChE activity to measure inhibition capacity. For this purpose, Ellman's method and the fast-blue salt method ${ }^{18,30}$ are the most commonly used approaches. However, these colorimetric methods based on color reactions show serious disadvantages due to the interference caused by colored extracts. As a result, very often no activity is detected because of the high dilution factor applied to the sample to avoid the interference of a noisy background. For this reason, fluorescence-based assays have been developed in this work to measure AChE and BChE activities, avoiding the interference of colored extracts. ABD-F reacts with thiols produced in the hydrolysis reaction between enzymes AChE/BChE and their substrate ATCI. The secondary reaction between $\mathrm{ABD}-\mathrm{F}$ and thiocholine forms highly fluorescent products that can be measured. AChE and BChE enzymatic activities were expressed as the $\mathrm{IC}_{50}$ value (concentration of extract that causes $50 \%$ inhibition), which means that the extract with the lowest $\mathrm{IC}_{50}$ is the one with the highest enzymatic inhibition activity. As can be seen in Table 4, extracts obtained with $\mathrm{NH}$ and ETAC present significantly $(p<0.05)$ greater AChE and BChE inhibition capacity. Although the $\mathrm{IC}_{50}$ values of the reference inhibitor galantamine hydrobromide $\left(0.40 \pm 0.01 \mu \mathrm{g} \mathrm{mL} \mathrm{m}^{-1}\right.$ and $2.15 \pm 0.26 \mu \mathrm{g} \mathrm{mL} \mathrm{m}^{-1}$ for AChE and $\mathrm{BChE}$, respectively) are lower than the values obtained for all the studied extracts, the use of compounds from natural sources is expected to have fewer side-effects and more bioavailability than synthetic inhibitors. ${ }^{31}$

These results are in line with previously published papers describing the potential AChE and BChE inhibition of aqueous extracts obtained from orange and other citrus fruit by-products, reporting $\mathrm{IC}_{50}$ values between 160 and $200 \mu \mathrm{g}$ $\mathrm{mL}^{-1} .^{32}$ The anti-cholinesterase activity of those water extracts was linked to the phenolic content and the presence of some monoterpenoids such as limonene. In our case, such correlation is not observed for TPC; in fact, as mentioned previously, the higher TPC value was obtained using EtOH (Table 3) that shows the lowest AChE and BChE inhibition. Besides, when correlations of enzymatic inhibition activities with TPC were conducted, significant exponential behaviors ( $p<0.01$ and 0.05 respectively) with high $r^{2}$ of 0.987 for AChE and 0.964 for BChE were achieved. In the same way, 
Table $4 \quad I C_{50}$ values from in vitro assays of different orange juice by-product extracts using AChE, BChE, LOX, ABTS, ROS and RNS assays

\begin{tabular}{|c|c|c|c|c|c|c|}
\hline Extract & $\begin{array}{l}\text { AChE } \\
\left(\mathrm{IC} 50 \mu \mathrm{g} \mathrm{mL}^{-1}\right)\end{array}$ & BChE & LOX & ABTS & ROS & RNS \\
\hline EtOH & $814 \pm 11^{\mathrm{a}}$ & $494 \pm 68^{\mathrm{a}}$ & $244 \pm 30^{\mathrm{a}}$ & $85.8 \pm 5.1^{b}$ & $11.5 \pm 1.2^{b}$ & $1090 \pm 170^{\mathrm{ab}}$ \\
\hline Ace & $337 \pm 36^{b}$ & $175 \pm 15^{b}$ & $90 \pm 2^{c}$ & $81.5 \pm 11.4^{b}$ & $5.2 \pm 0.4^{\mathrm{c}}$ & $834 \pm 87^{b c}$ \\
\hline ETAC & $179 \pm 25^{c}$ & $118 \pm 0^{b}$ & $130 \pm 17 b c$ & $84.1 \pm 7.7^{\mathrm{b}}$ & $5.5 \pm 0.8^{c}$ & $556 \pm 11^{c}$ \\
\hline $\mathrm{NH}$ & $167 \pm 13^{c}$ & $102 \pm 4^{b}$ & $116 \pm 21 b c$ & $175.4 \pm 15.6^{\mathrm{a}}$ & $20.0 \pm 0.8^{a}$ & $1278 \pm 197^{\mathrm{a}}$ \\
\hline Galantamine & $0.4 \pm 0.0^{\mathrm{d}}$ & $2.1 \pm 0.2^{\mathrm{c}}$ & & & & \\
\hline Quercetin & & & $125 \pm 20^{\mathrm{bc}}$ & & & \\
\hline Ascorbic acid & & & & $25 \pm 0.3^{c}$ & $1.2 \pm 0.0^{\mathrm{d}}$ & $1100 \pm 13^{\mathrm{ab}}$ \\
\hline
\end{tabular}

Different letters in the same column show significant differences $(p<0.05)$.

regressions with terpenoid families were built and significant exponential regressions were found versus sesquiterpenes and carotenoids ( $p<0.01 ; r^{2}>0.987$ for all of them). These results suggest that the lower the polarity of the solvent, the lower phenolic content and the higher amounts of C15 and C40 terpenoids are obtained, sharply increasing the inhibition of AChE and BChE.

Several terpenes described in the literature as AChE and BChE inhibitors have been found in our orange extracts. For example, monoterpenes such as limonene, (-)myrtenol, nerol, and $\alpha$-terpineol and sesquiterpenes such as $\beta$-caryophyllene, $\alpha$-copaene, guiaol nootkatone and elemol have been previously described as cholinesterase inhibitors. ${ }^{33}$

3.2.2. LOX in vitro assay. As for the anti-inflammatory capacity, all the evaluated extracts were found to be capable of inhibiting lipoxidase enzyme. LOX produces hydroperoxide conjugated dienes in the presence of LA and oxygen. Hydroperoxides can degrade the fluorescence of fluorescein. The velocity of fluorescence degradation with and without orange juice by-product extract was measured. Results reveal that Ace extracts exhibited the highest inhibition capacity, nearly followed by $\mathrm{NH}$ and ETAC (Table 4). In fact, these three extracts did not significantly $(p<0.05)$ differ from quercetin, used as the standard inhibitor, presenting an $\mathrm{IC}_{50}$ value of $125.72 \pm 20.72 \mu \mathrm{g} \mathrm{mL}{ }^{-1}$. Mono- and sesquiterpenes detected in our extracts, such as limonene and $\beta$-caryophyllene, have been reported as effective LOX inhibitors. ${ }^{34}$

3.2.3. ABTS, ROS and RNS assays. ABTS assay results show that EtOH, Ace and ETAC extracts produced similar antioxidant results, in contrast to the low antioxidant capacity of $\mathrm{NH}$ extract (Table 4). With regard to ORAC assay, Ace and ETAC were reported as extracts with the highest ROS scavenging capacity (Table 4). Nevertheless, none of the extracts were able to improve the control values given by ascorbic acid (ABTS $\mathrm{IC}_{50}$ $=25 \pm 0.36 \mu \mathrm{g} \mathrm{mL}{ }^{-1} ; \operatorname{ROS} \mathrm{IC}_{50}=1.29 \pm 0.09 \mu \mathrm{g} \mathrm{mL}{ }^{-1}$ ).

On the other hand, all the studied extracts were found to be capable of scavenging RNS (Table 4). ETAC extract results were significantly better $(p<0.05)$ than the ones of ascorbic acid, used as the antioxidant standard $\left(\mathrm{IC}_{50}=1100.91 \pm 13.96 \mu \mathrm{g}\right.$ $\mathrm{mL}^{-1}$ ), while the other three extracts gave similar results compared to the control values.

Antioxidant capacity from orange by products has been largely reported in the literature ${ }^{35}$ notwithstanding the anti- oxidant capacity was typically and entirely attributed to TPC. ${ }^{36}$ However, few literature reports can be found about the antioxidant properties of terpenes, among which monoterpenes such as nerol ${ }^{37}$ or sesquiterpenes such as valencene and guaiol, present in our extracts (above all in ETAC extract), stand out for their high antioxidant activity. ${ }^{38}$

3.2.4. Terpenoid BBB permeability evaluation. ETAC extract was selected for carrying out the PAMPA-BBB permeability assay due to its promising (and complete) neuroprotective in vitro capacity, and also since it contains all terpenoids. $\log P_{\mathrm{e}}$ was calculated in order to compare with previous studies; results are shown in Table 1 . As can be seen, hydrocarbons mono- and sesquiterpenoids like limonene or valencene (Fig. 1) showed the highest BBB permeability in terms of $\mathrm{cm} \mathrm{s}^{-1}$. Moreover, an increase of molecular weight and the presence of oxygenated groups seem to reduce the BBB permeability. In fact, some authors note the importance of lipophilicity and molecular size in natural molecules for the BBB permeability. ${ }^{13,39}$ Nevertheless, other molecular factors also contribute in BBB diffusion, such as Hansen polarity, topological polar surface area, hydrogen bond donors and ionization of compounds $\left(\mathrm{p} K_{\mathrm{a}}\right)$ among others. ${ }^{12}$ For these reasons, high molecular weight tocopherols and phytosterols, also present in our samples, can also cross the BBB, although less efficiently. From this work it can be concluded that terpenoids extracted from orange by-products have promising permeability across the $\mathrm{BBB}$ in comparison with other terpenoid structures ${ }^{23}$ or pharmacological drugs $\left(\log P_{\mathrm{e}} \mathrm{cm} \mathrm{s}^{-1} \pm\right.$ SD: Galantamine $=$ $-5.35 \pm 0.02$; Quercetin $=-7.02 \pm 0.08) .{ }^{40}$

\subsection{Relationship between bioactivity and chemical composition}

In an attempt to establish relationships between the content of terpenoid compounds in orange juice by-product extracts and their in vitro neuroprotective bioactivity, a multivariate data analysis based on principal components analysis (PCA) was carried out. PCA was performed including terpenoid concentration and the different in vitro bioactivity assay results (inhibition percentage) as variables. Therefore, connections could be established by proximity of the distributed samples and variables in the multivariate space. The first two dimensions of the PCA explain 97\% of the variance (see Fig. 3). The PCA plot reveals a clear separation between the four extracts. 


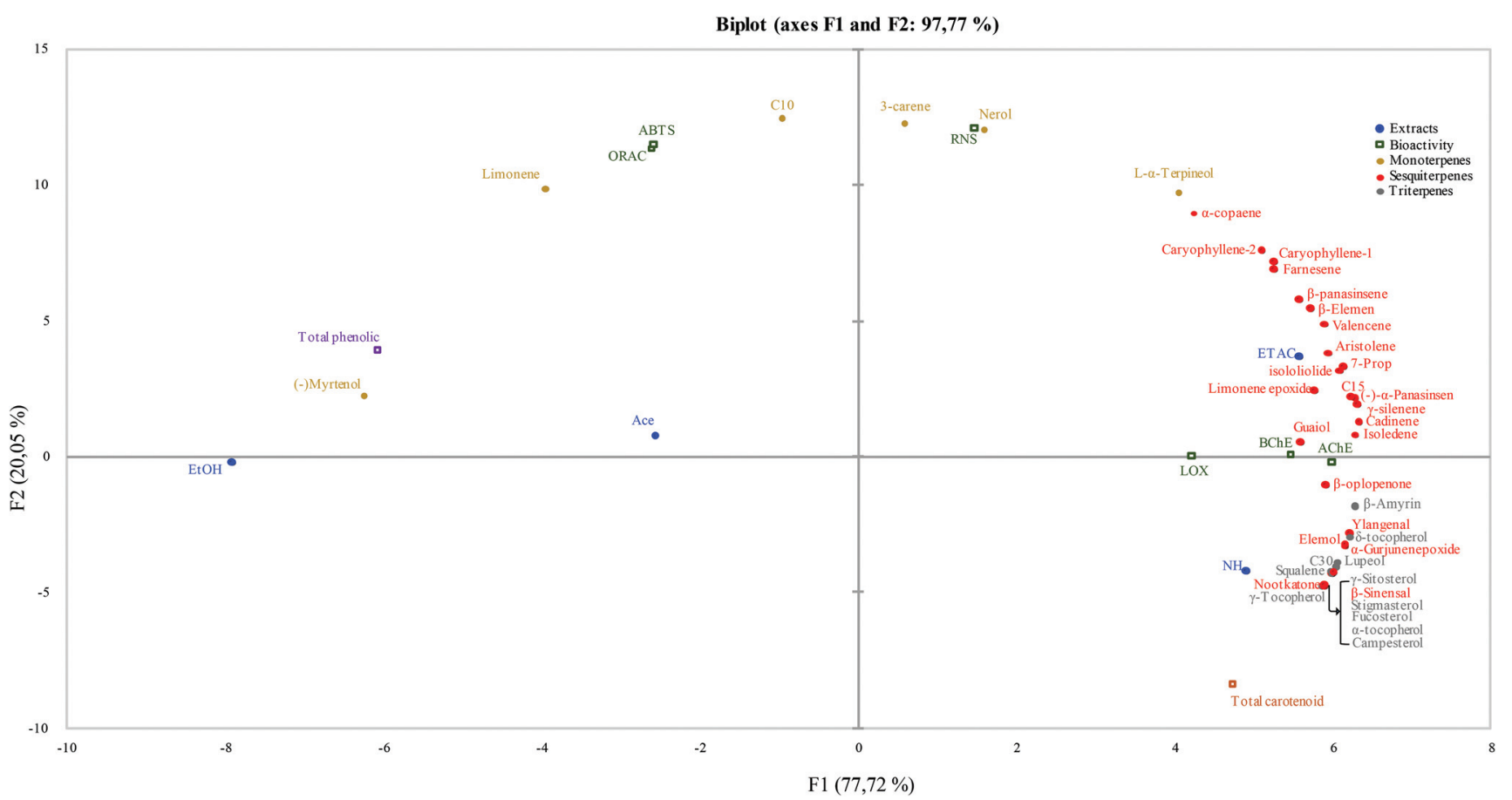

Fig. 3 PCA showing the projection of orange by-products extracts and different variables.

The PC1, which carries $77 \%$ of the variance, distributes the samples by increasing polarity order of the solvents. The main principal component also explains the general capacity of the solvents to extract terpenoids. The selectivity of ETAC towards C10 and C15 compounds can be clearly observed, whereas the use of $\mathrm{NH}$ as the extraction solvent should be the preferred choice to selectively extract $\mathrm{C} 30$ and C40 terpenoids. As expected, ethanol and acetone are the best solvents for phenolic compound extraction.

On the other hand, $\mathrm{PC} 2$ is related to the general in vitro protective activity of orange extracts. Thus, the samples and compounds distributed along the second principal component exhibit the lower (positive value in the PC2 axis) or higher (negative value in the PC2 axis) $\mathrm{IC}_{50}$ values for the tested in vitro assays. Therefore, the PCA plot suggests that ETAC extract exhibits the highest bioactive capacity (lower $\mathrm{IC}_{50}$ ), in agreement with the results shown in Table 4, for in vitro inhibition activity against AChE, BChE, LOX and protective activity against oxidative damage (ABTS, ROS, RNS). Furthermore, the lower correlation between ETAC extract and the total phenolic content explains the higher weight of terpene content, which contributes to an increased neuroprotective activity compared to other extracts. In contrast, EtOH extract is placed far away from all the enzymatic inhibition assay activities in the PCA plot, most probably due to the lower content in terpenoid compounds, whereas NH extracts negatively correlate with the antioxidant assay activities, as expected from their poor content in phenolic compounds.

Interestingly, the PCA plot shows a clear correlation between the protective action against oxidative damage (ABTS,
ROS, RNS) and the content of C10 (limonene, nerol, $\mathrm{L}$ - $\alpha$-terpineol, 3-carene). Terpenoids are a large group of molecular structures constituted by different isoprene units, capable of scavenging free radicals via hydrogen donation to form stable compounds. According to Graßmann (2005), ${ }^{41}$ the presence of a hydroxyl group in the isoprene skeleton of the terpene structure, like in $\alpha$-terpineol, seems to increase the antioxidant capacity. The same behavior could be observed for the other compounds such as phenolic mono/diterpenes (e.g., thymol or carnosol) and tocopherols.

As illustrated in the PCA plot, enzymatic inhibition activity seems to be associated with the presence of C15 terpenoids (such as $\gamma$-selinene or Guaiol). In this regard, the relationship between terpenoid molecular structures and AChE/BChE inhibition activity has been reported in the literature. ${ }^{33}$ In agreement with our results, some studies have shown that hydrocarbon sesquiterpenes like valencene are active against cholinesterase enzymes. ${ }^{33}$ In addition, the presence of oxygenated functional groups in the terpenoidal structure (e.g. terpineol) decreased inhibition activity. ${ }^{33}$ In a natural matrix from plants the presence of a high amount of sesquiterpenoids can lead to great inhibition capacity due to a synergic effect. ${ }^{33}$ Phytosterols like stigmasterol, based on a triterpenic structure, are reported to improve the cholinergic neurotransmission in adult rats. ${ }^{42}$ Regarding the type of terpenoid and anti-inflammatory capacity, Werz (2007) highlighted sesquiterpenoids and pentaciclic triterpenoids in LOX inhibition, by interfering between the active site of LOX and fatty acid substrate. Likewise, phenolic compounds present in orange peel have been described as LOX inhibitors. ${ }^{43}$ This fact might explain 
the best LOX inhibition value of acetone extract as a possible synergic effect of terpenoid and flavonoid compounds present in this extract. For this reason, we hypothesize that there might be a synergic effect between the above-mentioned terpenoids that might explain the neuroprotective activities evaluated in this paper, whose mechanism should be elucidated in future works.

\section{Conclusions}

In this work, extensive characterization, in terms of chemical composition and in vitro bioactivity assessment, demonstrates that industrial orange residues represent a promising source of neuroprotective terpenoids. Four extraction solvents, covering a wide range of polarities, have been tested for their capacity to enhance selective extraction of terpenes from orange juice by-products. Ethyl acetate extract showed the highest content of mono- and sesquiterpenes (e.g. L$\alpha$-terpineol, valencene), whereas extracts obtained in $n$-heptane extract exhibited the highest content of triterpenes (e.g. $\alpha$-tocopherol and $\gamma$-sitosterol). A set of bioactivity assays including enzymatic (AChE, BChE and LOX) and antioxidant (ABTS, ROS, RNS) activity testing was applied to investigate the neuroprotective potential of the target extract. A novel fluorescence-based methodology overcomes the drawbacks arising from the interference of colored extracts. Ethyl acetate extract is shown to be a promising source of terpenoids with anticholinergic activity and antioxidant capacity. A multivariate data analysis revealed correlation between some monoterpenes (e.g. nerol or limonene) and the antioxidant capacity of the extract, while a group of sesquiterpenes shows correlation with the tested AChE, BChE and LOX inhibition capacity. Moreover, orange waste terpenoids showed in vitro capacity to attain target tissue for neuroprotection activity; among them, hydrocarbon terpenoids present high permeability to cross the in vitro $\mathrm{BBB}$. The results of this research represent a step forward on the valorization of orange juice by-products, by attaining green organic extracts enriched in terpenoid compounds with potential in vitro neuroprotective capacity. Nevertheless, further in vitro (e.g. neuronal cells) and in vivo experiments are needed to fully evaluate the health-promoting properties of terpenoid-rich extracts from orange by-products, a promising source of nutraceuticals and functional foods to help $\mathrm{AD}$ prevention.

\section{Conflicts of interest}

There are no conflicts to declare.

\section{Acknowledgements}

J. D. S. M. would like to acknowledge the Ministry of science, innovation and universities for a FPU predoctoral grant FPU17/ 01876. G. A.-R. and M. B. would like to acknowledge the
Ministry of Economy and Competitiveness (MINECO) for their "Juan de la Cierva-Formación" postdoctoral grants FJCI-201525504 and FJCI-2016-30902, respectively. The authors also acknowledge the support from the AGL2017-89417-R project (MINECO).

\section{References}

1 B. Alquézar, A. Rodríguez, M. de la Peña and L. Peña, Genomic analysis of terpene synthase family and functional characterization of seven sesquiterpene synthases from citrus sinensis, Front. Plant Sci., 2017, 8, 1-20.

2 P. P. Brahmkshatriya and P. S. Brahmkshatriya, in Natural Products, Springer Berlin Heidelberg, Berlin, Heidelberg, 2013, 2665-2691.

3 A.-B. Cutillas, A. Carrasco, R. Martinez-Gutierrez, V. Tomas and J. Tudela, Rosmarinus officinalis L. essential oils from Spain: composition, antioxidant capacity, lipoxygenase and acetylcholinesterase inhibitory capacities, and antimicrobial activities, Plant Biosyst., 2018, 152, 1282-1292.

4 M. J. Murray and C. F. Murray, in Complications in Anesthesia, W.B. Saunders, Philadelphia, 2nd edn, 2007, pp. 493-495.

5 E. D. AlFadly, P. A. Elzahhar, A. Tramarin, S. Elkazaz, H. Shaltout, M. M. Abu-Serie, J. Janockova, O. Soukup, D. A. Ghareeb, A. F. El-Yazbi, R. W. Rafeh, N. M. Z. Bakkar, F. Kobeissy, I. Iriepa, I. Moraleda, M. N. S. Saudi, M. Bartolini and A. S. F. Belal, Tackling neuroinflammation and cholinergic deficit in Alzheimer's disease: Multi-target inhibitors of cholinesterases, cyclooxygenase-2 and 15-lipoxygenase, Eur. J. Med. Chem., 2019, 167, 161-186.

6 G. Mushtaq, N. Greig, J. Khan and M. Kamal, Status of Acetylcholinesterase and Butyrylcholinesterase in Alzheimer\&\#39;s Disease and Type 2 Diabetes Mellitus, CNS Neurol. Disord.: Drug Targets, 2014, 13, 1432-1439.

7 I. Silman and J. L. Sussman, Acetylcholinesterase: 'Classical' and 'non-classical' functions and pharmacology, Curr. Opin. Pharmacol., 2005, 5, 293-302.

8 Y. B. Joshi, P. F. Giannopoulos and D. Praticò, The 12/ 15-lipoxygenase as an emerging therapeutic target for Alzheimer's disease, Trends Pharmacol. Sci., 2015, 36, 181186.

9 H. Sadeghian and A. Jabbari, 15-Lipoxygenase inhibitors: a patent review, Expert Opin. Ther. Pat., 2016, 26, 65-88.

10 Oxidative Stress and Antioxidant Protection, ed. D. Armstrong and R. D. Stratton, Wiley, Hoboken, New Jersey, 2016.

11 F. Boora, E. Chirisa and S. Mukanganyama, Evaluation of Nitrite Radical Scavenging Properties of Selected Zimbabwean Plant Extracts and Their Phytoconstituents, J. Food Process., 2014, 2014, 1-7.

12 C. Greve and L. Jorgensen, Therapeutic Delivery, Ther. Delivery, 2016, 7, 117-138.

13 J. Zhu, X. Yi, J. Zhang, S. Chen and Y. Wu, Rapid screening of brain-penetrable antioxidants from natural products by 
blood-brain barrier specific permeability assay combined with DPPH recognition, J. Pharm. Biomed. Anal., 2018, 151, 42-48.

14 B. Gilbert-López, J. A. Mendiola, J. Fontecha, L. A. M. van den Broek, L. Sijtsma, A. Cifuentes, M. Herrero and E. Ibáñez, Downstream processing of Isochrysis galbana: a step towards microalgal biorefinery, Green Chem., 2015, 17, 4599-4609.

15 M. Herrero, F. Cacciola, P. Donato, D. Giuffrida, G. Dugo, P. Dugo and L. Mondello, Serial coupled columns reversedphase separations in high-performance liquid chromatography. Tool for analysis of complex real samples, J. Chromatogr. A, 2008, 1188, 208-215.

16 M. Koşar, H. J. D. Dorman and R. Hiltunen, Effect of an acid treatment on the phytochemical and antioxidant characteristics of extracts from selected Lamiaceae species, Food Chem., 2005, 91, 525-533.

17 A. D. P. Sánchez-Camargo, L. Montero, V. Stiger-Pouvreau, A. Tanniou, A. Cifuentes, M. Herrero and E. Ibáñez, Considerations on the use of enzyme-assisted extraction in combination with pressurized liquids to recover bioactive compounds from algae, Food Chem., 2016, 192, 67-74.

18 G. L. Ellman, K. D. Courtney, V. Andres and R. M. Featherstone, A new and rapid colorimetric determination of acetylcholinesterase activity, Biochem. Pharmacol., 1961, 7, 88-95.

19 M. Whent, T. Ping, W. Kenworthy and L. Yu, High-throughput assay for detection of soybean lipoxygenase-1, J. Agric. Food Chem., 2010, 58, 12602-12607.

20 R. Re, N. Pellegrini, A. Proteggente, A. Pannala, M. Yang and C. Rice-Evans, Antioxidant activity applying an improved ABTS radical cation decolorization assay., Free Radicals Biol. Med., 1999, 26, 1231-1237.

21 B. Ou, M. Hampsch-Woodill and R. L. Prior, Development and validation of an improved oxygen radical absorbance capacity assay using fluorescein as the fluorescent probe, J. Agric. Food Chem., 2001, 49, 4619-4626.

22 S. C. Ho, Y. L. Tang, S. M. Lin and Y. F. Liew, Evaluation of peroxynitrite-scavenging capacities of several commonly used fresh spices, Food Chem., 2010, 119, 11021107.

23 A. Könczöl, K. Rendes, M. Dékány, J. Müller, E. Riethmüller and G. T. Balogh, Blood-brain barrier specific permeability assay reveals $\mathrm{N}$-methylated tyramine derivatives in standardised leaf extracts and herbal products of Ginkgo biloba, J. Pharm. Biomed. Anal., 2016, 131, 167-174.

24 X. Chen, A. Murawski, K. Patel, C. L. Crespi and P. V. Balimane, A novel design of artificial membrane for improving the PAMPA model, Pharm. Res., 2008, 25, 15111520.

25 B. Rivas, A. Torrado, P. Torre, A. Converti and J. M. Domínguez, Submerged citric acid fermentation on orange peel autohydrolysate, J. Agric. Food Chem., 2008, 56, 2380-2387.

26 R. Gallego, M. Bueno and M. Herrero, Sub- and supercritical fluid extraction of bioactive compounds from plants, food-by-products, seaweeds and microalgae - An update, TrAC, Trends Anal. Chem., 2019, 116, 198-213.

27 A. E. Hegazy and M. I. Ibrahium, Antioxidant activities of orange peel extracts, World Appl. Sci. J., 2012, 18, 684-688.

28 R. K. Saini and Y. S. Keum, Carotenoid extraction methods: A review of recent developments, Food Chem., 2018, 240, 90-103.

29 D. C. Liu, Q. Zeng, Q. X. Ji, C. F. Liu, S. B. Liu and Y. Liu, A comparison of the ultrastructure and composition of fruits' cuticular wax from the wild-type 'Newhall' navel orange (Citrus sinensis [L.] Osbeck cv. Newhall) and its glossy mutant, Plant Cell Rep., 2012, 31, 2239-2246.

30 T. L. Vincent, P. J. Green and D. N. Woolfson, Detection and identification of acetylcholinesterase inhibitor compounds in Annona cherimola Mill. by effect-directed analysis using thin layer chromatography-bioassay-mass spectrometry, Phytochem Anal., 2011, 30, 4-11.

31 G. W. Small, P. V. Rabins, P. P. Barry, N. S. Buckholtz, S. T. DeKosky, S. H. Ferris, S. I. Finkel, L. P. Gwyther, Z. S. Khachaturian, B. D. Lebowitz, T. D. McRae, J. C. Morris, F. Oakley, L. S. Schneider, J. E. Streim, T. Sunderland, L. A. Teri and L. E. Tune, Diagnosis and treatment of Alzheimer disease and related disorders. Consensus statement of the American Association for Geriatric Psychiatry, the Alzheimer's Association, and the American Geriatrics Society, J. Am. Med. Assoc., 1997, 278, 1363-1371.

32 A. O. Ademosun and G. Oboh, Anticholinesterase and antioxidative properties of water-extractable phytochemicals from some citrus peels, J. Basic Clin. Physiol. Pharmacol., 2014, 25, 199-204.

33 O. Politeo, F. Burcul, I. Blazevic and M. Radan, Terpenes, Phenylpropanoids, Sulfur and Other Essential Oil Constituents as Inhibitors of Cholinesterases, Split, Croatia, 2018, vol. 25.

34 S. Baylac and P. Racine, Inhibition of 5-lipoxygenase by essential oils and other natural fragment extracts, Int. J. Aromather., 2003, 13, 138-142.

35 S. Rafiq, R. Kaul, S. A. Sofi, N. Bashir, F. Nazir and G. A. Nayik, Citrus peel as a source of functional ingredient: A review, J. Saudi Soc. Agric. Sci., 2018, 17, 351358.

36 W. Y. Ho, S. S. Liew, S. K. Yeap, S. Adzni and B. Sharifudin, Phytochemical composition and in vitro antioxidant activities of Citrus sinensis peel extracts, PeerJ, 2018, 6, 5331, DOI: $10.7717 /$ peerj.5331.

37 E. Gonzalez-Burgos and M. P. Gomez-Serranillos, Terpene Compounds in Nature: A Review of Their Potential Antioxidant Activity, Curr. Med. Chem., 2012, 19, 53195341.

38 K. Liu, Q. Chen, Y. Liu, X. Zhou and X. Wang, Isolation and Biological Activities of Decanal, Linalool, Valencene, and Octanal from Sweet Orange Oil, J. Food Sci., 2012, 77, C1156-C1161.

39 S. Agatonovic-Kustrin, C. K. Y. Chan, V. Gegechkori and D. W. Morton, Models for skin and brain penetration of major components from essential oils used in aromather- 
apy for dementia patients, J. Biomol. Struct. Dyn., 2020, 38, 2402-2411.

40 Á. Könczöl, J. Müller, E. Földes, Z. Béni, K. Végh, Á. Kéry and G. T. Balogh, Applicability of a blood-brain barrier specific artificial membrane permeability assay at the early stage of natural product-based CNS drug discovery, J. Nat. Prod., 2013, 76, 655-663.

41 J. Graßmann, Terpenoids as Plant Antioxidants, Vitam. Horm., 2005, 72, 505-535.

42 T. Vanmierlo, J. F. J. Bogie, J. Mailleux, J. Vanmol, D. Lütjohann, M. Mulder and J. J. A. Hendriks, Plant sterols: Friend or foe in CNS disorders?, Prog. Lipid Res., 2015, 58, 26-39.

43 O. Werz, Inhibition of 5-lipoxygenase product synthesis by natural compounds of plant origin, Planta Med., 2007, 73, 1331-1357.

44 W. Zhou, M. Yoshioka and H. Yokogoshi, Sub-chronic effects of s-limonene on brain neurotransmitter levels and behavior of rats, J. Nutr. Sci. Vitaminol., 2009, 55, 367-373.

45 G. Vieira, J. Cavalli, E. C. D. Gonçalves, S. F. P. Braga, R. S. Ferreira, A. R. S. Santos, M. Cola, N. R. B. Raposo, R. Capasso and R. C. Dutra, Antidepressant-like effect of terpineol in an inflammatory model of depression: Involvement of the cannabinoid system and D2 dopamine receptor, Biomolecules, 2020, 10, 1-23.

46 X. S. Wu, T. Xie, J. Lin, H. Z. Fan, H. J. Huang-Fu, L. F. Ni and H. F. Yan, An investigation of the ability of elemene to pass through the blood-brain barrier and its effect on brain carcinomas, J. Pharm. Pharmacol., 2009, 61, 1653-1656.

47 K. Weston-Green, Recent Advances in Cannabinoid Research, IntechOpen, 2019.

48 A. Sakhteman, A. Pasdaran, M. Afifi and A. Hamedi, An Assay on the Possible Effect of Essential Oil Constituents on Receptors Involved in Women's Hormonal Health and
Reproductive System Diseases, J. Evidence-Based Integr. Med., 2020, 25, 1-9, DOI: 10.1177/2515690X20932527.

49 B. He, F. Xu, F. Xiao, T. Yan, B. Wu, K. Bi and Y. Jia, Neuroprotective effects of nootkatone from Alpiniae oxyphyllae Fructus against amyloid- $\beta$-induced cognitive impairment, Metab. Brain Dis., 2018, 33, 251-259.

50 N. E. Craft, T. B. Haitema, K. M. Garnett and K. A. Fitch, Carotenoid, tocopherol, and retinol concentrations in elderly human brain, J. Nutr. Health Aging, 2004, 8, 156162.

51 A. Malik, U. Jamil, T. T. Butt, S. Waquar, S. H. Gan, H. Shafique and T. H. Jafar, In silico and in vitro studies of lupeol and iso-orientin as potential antidiabetic agents in a rat model, Drug Des., Dev. Ther., 2019, 13, 15011513.

52 S. I. Maslikah, S. R. Lestari, N. Handayani, N. A. N. N. Malek, K. B. Jemon, A. Amalia and S. Afifah, Study on molecular docking of Red Betel (Piper crocatum Ruiz \& Pav.) active compound and tamoxifen drug as an inhibitor of Estrogen receptor- $\alpha(E R-\alpha)$ that plays a role in breast cancer, AIP Conf. Proc., 2020, 2232, 040001, DOI: https://doi.org/10.1063/5.0002556.

53 Q. Lu, N. Huang, Y. Peng, C. Zhu and S. Pan, Peel oils from three Citrus species: volatile constituents, antioxidant activities and related contributions of individual components, J. Food Sci. Technol., 2019, 56, 4492-4502.

54 L. K. Ng and M. Hupé, Analysis of sterols: A novel approach for detecting juices of pineapple, passionfruit, orange and grapefruit in compounded beverages, J. Sci. Food Agric., 1998, 76, 617-627.

55 F. Anwar, R. Naseer, M. I. Bhanger, S. Ashraf, F. N. Talpur and F. A. Aladedunye, Physico-chemical characteristics of citrus seeds and seed oils from Pakistan, JAOCS, J. Am. Oil Chem. Soc., 2008, 85, 321-330. 